\title{
Rendimento escolar do aluno com Síndrome de Down (SD) após as férias de verão: influência da qualidade de vida e estimulação recebida da família.
}

Claudilene Aparecida Pandorf

Josiane Mello

Antonio Carlos de Francisco

Ana Cláudia de Oliveira

Elson Heraldo Ribeiro Junior

\section{Resumo}

Este artigo é resultado de uma pesquisa desenvolvida na monografia de conclusão do curso de Pós-Graduação em Educação Especial de uma Faculdade privada no Estado do Paraná. Tal pesquisa foi desenvolvida, no final e no início dos anos letivos de 2006 e 2007, com o objetivo de pesquisar a respeito da qualidade de vida, que alunos com SD, vivenciavam durante as férias de verão, e a sua influência no rendimento escolar, levando em consideração o estímulo recebido da família. $O$ estudo foi realizado com alunos do ensino fundamental, do 1 음 ao 5 응 ano, observando o quanto a estimulação recebida por parte da família, nas férias de verão, afeta os conhecimentos adquiridos durante o ano letivo, aquisição de novos conhecimentos, bem como a manutenção destes, após o período das férias de verão. Para a realização da pesquisa foram abordados alunos, pais e professores, em dois períodos diferentes, o final do 4 o período letivo de 2006 e o início do 1 o período letivo de 2007, com o intuito de investigar: Quais foram os conhecimentos adquiridos pelos alunos com SD durante o 4 bimestre do ano letivo de 2006? Qual a percepção dos pais no tocante a importância da estimulação e qualidade de vida durante as férias escolares dos alunos SD? Quais as atividades proporcionadas pelos pais durante as férias escolares dos alunos com SD? E se existe integração entre a escola e a família no processo de estimulação e qualidade de vida dos alunos com SD? Os resultados deste estudo revelaram que não houve retrocesso significativo quanto aos conteúdos assimilados antes das férias escolares, pois as famílias proporcionaram atividades e estimulação voltadas para este fim, garantindo a qualidade de vida para seus filhos com SD. Também foi constatado que ficou a desejar a integração entre a escola e a família no processo ensino aprendizagem dos alunos SD.

Palavras-chave: Qualidade de vida, Férias, Síndrome de Down. Rendimento escolar.

\section{Abstract}

This paper is the result of a research developed in the monograph of completion of the postgraduate course in special education from a private college in the State of Paraná. Such research was developed at the end and at the beginning of the school years of 2006 and 2007, with the goal of searching regarding quality of life, that students with SD, you experienced during the summer holidays, and its influence on academic achievement, taking into 
consideration the stimulus received from the family. The study was conducted with elementary students, from 1st to 5th year, noting how the stimulation received by the family, in the summer holidays, affects the knowledge gained during the school year, acquisition of new knowledge, as well as the maintenance of these, after the summer vacation period. For the realization of the survey were approached SD students, parents and teachers, in two different periods, the end of the 4th term of 2006 and the beginning of the first term of 2007, in order to investigate: what were the knowledge acquired by students during the 4th quarter of the SD school year of 2006? What is the perception of parents regarding the importance of stimulation and quality of life during school holidays SD students? What are the activities offered by the parents during school holidays SD students? And if there is integration between the school and family in the process of stimulation and SD students ' quality of life? Is the result of a research developed in the monograph of completion of the postgraduate course in special education from a private college in the State of Paraná. Such research was developed at the end and at the beginning of the school years of 2006 and 2007, with the goal of searching regarding quality of life, that students with SD, you experienced during the summer holidays, and its influence on academic achievement, taking into consideration the stimulus received from the family. The study was conducted with elementary students, from 1st to 5th year, noting how the stimulation received by the family, in the summer holidays, affects the knowledge gained during the school year, acquisition of new knowledge, as well as the maintenance of these, after the summer vacation period. For the realization of the survey addressed students, parents and teachers, in two different periods, the end of the 4th term of 2006 and the beginning of the first term of 2007, aiming to check how the parents recognize the need for stimulation of the wearer of Down syndrome during the holidays, and if so, how parents and students work with this stimulation by increasing the quality of life of their children. The results of this study showed that there was no significant backlash regarding the contents before the school holiday assimilated because families provided stimulation and activities geared toward this end, ensuring the quality for their children was also found that SD is no integration between the school and family in the process of students learning teaching SD.

Key words: Quality of life. Holiday. Down syndrome. School performance. 


\title{
Introdução
}

No início do século XIX já havia estudos sobre a Síndrome de Down. As propostas de estudos e pesquisas foram avançando e atuando diretamente no preconceito que havia sobre o assunto, por falta de conhecimentos científicos.

Hoje, de acordo Silva (2002), sabe-se que Síndrome de Down se faz presente na concepção devido um erro genético. Podendo este erro, ocorrer no momento ou logo após a concepção.

Castro e Pimentel (2009, p. 304) esclarecem que:

\begin{abstract}
"a Síndrome de Down é um acidente genético que ocorre no par do cromossomo 21, com a presença de um cromossomo extra. Por isso, essa síndrome é também chamada de trissomia 21. A presença extra desse cromossomo acarreta no desenvolvimento intelectual um retardo leve ou moderado, em virtude de alterações cerebrais".
\end{abstract}

Observa-se, que mesmo com o grande avanço das pesquisas, ainda há muito preconceito por parte da sociedade, no que se refere às pessoas com Síndrome de Down, seja por falta de acesso e/ou falta de interesse em buscar informações a respeito deste tema, ou devido às lacunas que ainda existem, e que a comunidade científica está tentando suprimir.

Sabe-se que para algumas pessoas, o indivíduo com SD é considerado incapaz de exercer uma atividade profissional e/ou até mesmo viver na sociedade. Num passado não muito distante, esses indivíduos eram vistos e tratados pela sociedade e até mesmo pelos próprios pais, como seres dignos de piedade. De um modo geral, não era comum a família levar um filho com SD a um evento social, o que acabava comprometendo a qualidade de vida de ambos.

$\mathrm{Na}$ atualidade, é consensual que um indivíduo SD pode e deve levar uma vida normal, desenvolvendo as mais diversas atividades diárias, levando em conta suas limitações relativas ao seu ao grau de comprometimento, mas nunca deixando que estas façam valer mais para sua vida diária do que suas potencialidades. Estas devem ser estimuladas e desenvolvidas para maior autonomia dos alunos com SD na sociedade.

Nesta direção, esta pesquisa tem por objetivo geral investigar a qualidade de vida que esses alunos vivenciaram durante as férias de verão, e a sua influência no rendimento escolar, levando em consideração o estímulo recebido da família. E por objetivos específicos: identificar quais foram os conhecimentos adquiridos pelos alunos com SD durante o 40 bimestre do ano letivo de 2006? Qual a percepção dos pais no tocante a importância da estimulação e qualidade de vida durante as férias escolares dos alunos SD? Quais as atividades proporcionadas pelos pais 
durante as férias escolares dos alunos com SD? E se existe integração entre a escola e a família no processo de estimulação e qualidade de vida dos alunos com SD?

Um dos eixos hipotéticos, norteador desta pesquisa era verificar se os alunos com SD, quando da volta às aulas, apresentavam prejuízos no tocante à aquisição dos conhecimentos adquiridos no bimestre letivo anterior. Ideia essa que ficou evidenciada na pesquisa.

Ao leitor, propõem-se uma visão de como ocorre a estimulação da criança com SD durante o período de férias escolares de final/começo de ano letivo. Para tanto se recorreu a um referencial teórico para embasar a pesquisa e analisou-se um grupo formado por alunos com SD, seus pais e professores. Coletou-se informações importantes a todos que estão envolvidos com o desenvolvimento escolar e social do aluno com SD, professores, cuidadores, seus pais, a família como um todo e a comunidade em que está inserida, levando em consideração a qualidade de vida.

\section{A Síndrome de Down}

Quem nasce com Síndrome de Down tem um cromossomo a mais. O excesso de material genético pode vir do óvulo ou do espermatozoide e ocorre no cromossomo 21.

Murta, Ávila e Moran (2002) colocam que é a mais comum anomalia de cromossomos, e é chamada de Trissomia do cromossomo 21. A síndrome não escolhe classe social, nem raça, sendo registrada em todo o mundo indiscriminadamente.

Moreira e Gusmão (2002) afirmam que:

"A anomalia se deve à presença de um cromossomo 21 adicional e ocorre como trissomia livre em cerca de $95 \%$ dos casos. Nesse distúrbio podem ser também observadas outras formas de trissomia que podem ocorrer em mosaicismo, com células normais, e outras com trissomia 21 em 1\% a 2\% dos portadores da síndrome, além de translocações geralmente entre os cromossomos 14 e 21 em cerca de 3\% a 4\% dos casos. Na maioria das vezes, o distúrbio cromossômico deve-se à mutação de novo, sem chances maiores de recorrência na família".

A síndrome ocasiona características físicas próprias, ou seja, o indivíduo com SD pode ser um pouco mais baixo e ter o tamanho dos pés e das mãos pequenos quando comparado a outras pessoas; podem ainda ter tendência à obesidade; apresentar maior risco de doença cardíaca; maior risco de deficiência visual; e menor tônus muscular.

Segundo Silva (2002), as muitas alterações estruturais e funcionais do sistema nervoso do SD determinam algumas de suas características mais marcantes, como distúrbios de aprendizagem e de desenvolvimento.

R. B. E. C. T., vol 6, núm. 3, set-dez.2013 ISSN - 1982-873X 
Para minimizar esses distúrbios e atrasos no desenvolvimento é necessário, que desde o nascimento, a criança receba estímulos adequados para otimizar suas potencialidades. É imprescindível que a família da criança com SD receba orientações de profissionais das áreas da saúde e da educação, visando o desenvolvimento e vitalidade com qualidade desses indivíduos.

Zaqueu e Mello (2008, p.13) pontuam que:

"a ocorrência do Mal Alzheimer (MA) em indivíduos com síndrome de Down é quase inevitável, pois quase todos os trissômicos acima de 40 anos apresentam evidências neuropatológicas dessa doença, mas o quadro clínico torna-se evidente somente por volta dos 60 anos".

Esta afirmação vem ao encontro do que se verifica quanto à expectativa de vida desses indivíduos que aumentou consideravelmente, estando hoje em torno de 60 anos. Isso é resultante dos avanços da medicina que beneficiam o indivíduo com SD. A perspectiva de vida com qualidade aumenta devido a fatores como prevenção de doenças cardíacas, controle da obesidade e do colesterol, orientação nutricional, exercícios físicos, entre outros.

\section{Características principais da criança com SD}

A síndrome de Down apresenta características pontuais, que podem ser observadas no ato do nascimento, pelas alterações fenotípicas semelhantes.

Segundo Luiz et al. (2008), as crianças com SD podem apresentar estatura mais baixa, em relação a outras crianças, hipotonia, mãos diferenciadas por serem pequenas e largas com uma única prega palmar e articulações bem flexíveis.

Estes mesmos autores ressaltam que, para identificar um indivíduo com SD, num primeiro momento, basta olhar atentamente para a sua face. Esta região é larga e achatada, os olhos são distantes um do outro, a base nasal é achatada, a língua pode ser um pouco projetada para fora da boca (protusa), o nariz tem um formato menor, em relação ao de outros indivíduos e entre outros sinais apresentados. A cardiopatia congênita se caracteriza como um preocupante no SD. O desenvolvimento da linguagem é mais lento, provocando maiores atrasos, necessitando de estimulação precoce, pois é por meio da linguagem, que a criança interage com o meio que o cerca, sendo esta peça fundamental no processo de ensino aprendizagem. É comum, nos primeiros dias ocorrer dificuldades na sucção e deglutição, que serão atenuadas com o passar do tempo.

No tocante aos fenótipos, que caracterizam o aspecto geral dos indivíduos com SD, Castro e Pimentel (2009) apontam as diferenças quanto aos aspectos do desenvolvimento geral e colocam que as crianças com SD se desenvolvem, diferentemente, na aquisição da linguagem e motricidade. Também há diferenças quanto às aquisições de habilidades para a vida cotidiana e 
sua socialização. Em relação ao desenvolvimento físico, este se distingue por ser mais lento e ocorre atraso no desenvolvimento motor, que se compromete nos primeiros meses devido à hipotonia.

É sabido, que há diversos graus de comprometimento no desenvolvimento físico de um indivíduo com SD, nem todos possuem todos os fenótipos. A deficiência mental se apresenta em maior ou menor grau em diferentes indivíduos.

Hoje já é possível identificar durante a gestação a presença da Síndrome de Down, por meio do ultrassom morfológico fetal e pelos exames de amniocentese e amostra do vilo corial.

Depois do nascimento, o diagnóstico clínico é comprovado pelo exame do cariótipo (estudo dos cromossomos), que também ajuda a determinar o risco, em geral baixo, de recorrência da alteração em outros filhos do casal.

Assim, de posse da confirmação da SD, recomenda-se que seja iniciada imediatamente a intervenção precoce, para que esta criança com SD seja estimulada a vencer suas limitações, que foram impostas por esta patologia genética. A família tem um importante papel neste processo, juntamente com a ajuda de uma equipe profissional multidisciplinar, pois a criança com SD tem necessidades específicas de saúde e aprendizagem, o que vai demandar destes esforços e metodologias para habilitá-la a conviver com qualidade de vida e participar da sociedade.

\section{Pedagogia, criança com SD e integração escola e família}

A criança com SD apresenta muitas limitações que podem ser trabalhadas pelo pedagogo, levando em consideração sempre o ritmo que varia de indivíduo para indivíduo, propiciando estimulação adequada num trabalho planejado onde podem ser minimizadas debilidades $\mathrm{e}$ desenvolvidas potencialidades. É bom que se crie um programa de acordo com as necessidades específicas de cada criança, pois nem todas tem o mesmo grau de comprometimento.

O pedagogo é um profissional de extrema relevância para o desenvolvimento cognitivo da criança com SD. Moreira, EL-Hani e Gusmão (2000) afirmam que,

"as habilidades intelectuais de um individuo Down têm sido historicamente subestimadas. O pedagogo vem ajudar a mudar esta visão sobre a criança $S D$, trabalhando com ela para obter um maior desenvolvimento dentro das suas potencialidades, realizando e orientando pais e professores nos procedimentos de intervenção precoce no desenvolvimento da criança".

Este profissional possibilita a abertura de novos caminhos para o desenvolvimento cognitivo da criança, visto as implicações causadas pelo déficit que a síndrome causa, propiciando maior autonomia e adaptação na sociedade. 
Nesse sentido Bartalotti (2004, p. 46) pontua que,

" as especificidades das pessoas com SD devem ser, então, consideradas e conhecidas pelos profissionais que com elas lidam, de forma a otimizar o processo de ensino e aprendizagem, a fim de propiciar o seu desenvolvimento, entendido aqui como a apropriação, pelo indivíduo da cultura humana, que deve caminhar em direção à independência e à autodeterminação".

Dentro das escolas no ensino regular, vem sendo utilizadas práticas pedagógicas para atender essas diferenças dos indivíduos. Para tanto os materiais e equipamentos vão sendo adaptados às necessidades de cada criança utilizando metodologias, procedimentos diferenciados e atendimento de professores especializados que podem solicitar revisão médica e psicológica. Silva (2002).

Em se tratando de crianças com Síndrome de Down, o reforço extracurricular é de muita valia. Segundo Castro e Pimentel (2009, p. 304),

"é preciso haver investimentos externos para que a criança com Síndrome de Down possa amadurecer as funções neurológicas, executar atividades diárias e, consequentemente, aprender e se desenvolver. Vale ressaltar que não se quer aqui esquecer que existem alterações no processo de internalização de conceitos que dificultarão a construção dos conhecimentos e, sobretudo, na aquisição da linguagem. Porém, para amenizar as dificuldades é preciso que, no contexto escolar, o professor conheça e estimule capacidades de desenvolvimento desses sujeitos".

Quanto ao conteúdo a ser trabalhado na escola estão previstas adaptações curriculares, necessárias para o ensino inclusivo. $O$ ensino para esse aluno deve ser feito de forma sistemática, mas sem ser enfadonha e ter como objetivo promover sua autonomia por meio da integração na família, escola e sociedade, adequando o desenvolvimento volitivo, afetivo e também cognitivo. A criança com SD precisa ainda trabalhar percepção corporal.

O aprendizado deve acontecer de forma o mais espontânea possível com material concreto e diversificado. Estando atento para o cuidado em não exagerar na estimulação ou exigir da criança o que ela ainda não pode fazer, para não desmotivá-la.

A inclusão na escola e sociedade tende a neutralizar preconceitos. A educação inclusiva assegura aos pais o direito de escolher a escola de seu filho. A escola para o aluno com SD deve favorecer o aprendizado através de métodos alternativos, como no caso da alfabetização, respeitando as diferenças individuais. (SILVA, 2002).

A escola inclusiva possibilita interação social ao aluno com SD, colaborando para o seu desenvolvimento e inclusão na sociedade. A busca da qualidade de vida passa pela conquista da 
autonomia pessoal e social, levando em conta o fator independência que ela possa alcançar. (CASTRO E PIMENTEL, 2009).

Este fator independência alcançado é resultado de ações conjuntas da escola inclusiva e da família, tendo em mente que a criança com SD, pelo processo natural da vida, se tornará um jovem com SD e em breve um adulto com SD, esses agentes precisam focar na educação para o trabalho e para a qualificação profissional.

\section{Estimulação por parte da família durante as férias escolares dos alunos com SD}

O nascimento de uma criança com SD repercute em toda a família, evidenciando a necessidade de apoio aos seus membros, em especial, fornecendo informação e acolhendo-os adequadamente para buscarem a melhor forma de reorganização familiar. (NUNES, DUPAS, 2011).

"No início, surgem inúmeros questionamentos: o que é a SD? O que fazer daqui para frente? Onde levar a criança? O que é oferecido à criança e à família? Com o passar do tempo, as necessidades se modificam a cada nova fase de desenvolvimento que a criança atravessa, precisando de aprendizado constante". (NUNES, DUPAS, 2011).

A primeira estimulação da criança com SD deve-se iniciar no lar, por meio da interação dos familiares, pois o desenvolvimento vai depender da qualidade dos estímulos e cuidados oferecidos. Nesse sentido, a família deve ser motivada a participar e colaborar com a educação e desenvolvimento da criança por meio de uma interação.

Hoje existem várias instituições e profissionais especializados, que orientam pais e outros membros familiares (ou não), no tocante aos cuidados e estímulos com uma criança com SD.

Segundo Cunha, Assis e Fiamenghi Jr (2002) é necessária a adaptação dos pais e a reorganização da família que passa pelo impacto de ter um filho com a síndrome e que tem dificuldade de aceitar o diagnóstico. A família passa por uma fase, um tempo para aceitação. Um assistente Social pode proporcionar ajuda para os pais na busca dos recursos para o desenvolvimento do seu filho. Faz-se necessário encaminhar a família e o bebê para profissionais que trabalham na estimulação global como fisioterapeutas, fonoaudiólogos, pedagogos e psicólogo, para que possam auxiliar no desenvolvimento da criança.

Nunes e Dupas (2011) apontam que:

"Para ajudar ao máximo o desenvolvimento da criança, a família impõe para si a necessidade de aprender para colaborar mais, estimular mais para que ela evolua, visando o melhor para o seu futuro. Para que a criança se desenvolva e 
supere suas próprias barreiras, a família se mobiliza, indo à luta, buscando todo tipo de tratamento necessário (fonoaudiólogo, fisioterapeuta, psicólogo, pedagogo...), querendo encontrar serviços e profissionais que possam atender a criança com eficácia, e, ainda, busca conhecimento visando aprender para dar continuidade a esses estímulos em casa".

A criança com SD deve receber cuidados especiais para o seu bom desenvolvimento (GARCIA, ROTH e SOBREIRO ,1991), apesar de necessitar dos mesmos cuidados clínicos, que qualquer outra criança, em algumas situações exigem mais cuidados e atenção. Como por exemplo: devem-se evitar movimentos bruscos com o bebê, pois este tem as duas primeiras vértebras do pescoço mais frágeis. A amamentação apresenta certo grau de dificuldade devido ao baixo tônus muscular. A maioria das crianças SD apresenta dificuldades de audição e podem ocorrer, em muitos casos, doença congênita do coração necessitando algumas vezes de cirurgia. Há de se observar possíveis problemas oculares, deficiência de hormônios tireoidianos e alguns outros problemas característicos.

Portanto é necessário que a família esteja atenta e proporcione à criança com SD além da estimulação necessária o devido acompanhamento médico.

De acordo com Nunes e Dupas (2011), a família deve buscar o melhor desenvolvimento da criança, fornecendo estímulos constantes para que a criança se torne um adulto o mais independente possível.

Cabe à família aprender a lidar com essa nova situação: ter em casa um membro com a síndrome. A família passa a viver em função da criança. Precisará levar a criança a médicos para saber se existe algum problema de saúde associado à síndrome. Buscar saber sobre a síndrome e procurar agir precocemente para não perder tempo e fazer todo o possível para estimular a criança, mesmo em casa, acreditando nas perspectivas futuras. A criança precisará de acompanhamento e estimulação constante e intensa, tornando uma grande responsabilidade para a família. Esta se vê em voltas com aumento de gastos necessitando de ajuda financeira e emocional para o enfrentamento dos momentos difíceis. Um ponto de apoio importante é o contato com outras famílias que partilham de vivências semelhante, diminuindo as dúvidas pois se comunicam e disseminam informações, reconfortando-se mutuamente. A família soma esforços em busca da maior autonomia e independência que a criança possa alcançar. (NUNES, DUPAS, 2011). 


\section{Procedimentos metodológicos \\ Caracterização da pesquisa}

Esta pesquisa caracteriza-se como aplicada, qualitativa, exploratória, descritiva, e estudo de caso.

Pesquisa aplicada, pois com relação a sua natureza, objetiva gerar conhecimentos para aplicação prática visando à resolução de problemas específicos (GIL, 2009). Assim, esta pesquisa pretende identificar a respeito da qualidade de vida, que os alunos com SD, vivenciavam durante as férias de verão, e a sua influência no rendimento escolar, levando em consideração o estímulo recebido da família.

Quanto à abordagem do problema, esta pesquisa caracteriza-se como qualitativa. Qualitativa, por exigir a interpretação dos fenômenos e a atribuição de significados. (GIL, 2009).

Do ponto de vista dos objetivos, esta pesquisa é exploratória e descritiva. Exploratória, devido à familiaridade com o problema estudado e entrevistas com a os atores envolvidos (professores, pais e alunos). E descritiva, por descrever as características da população e do fenômeno estudado estabelecendo relações entre eles, por meio do uso de técnicas padronizadas de coleta de dados, como questionário e entrevista.

No que se refere aos procedimentos técnicos, trata-se de um estudo de caso, por envolver um estudo a respeito da qualidade de vida, que alunos com SD, vivenciavam durante as férias de verão, e a sua influência no rendimento escolar, levando em consideração o estímulo recebido da família.

\section{Delimitação da pesquisa}

Esta pesquisa foi desenvolvida em três escolas de educação especial, duas públicas e uma particular. A amostra foi constituída por dez participantes. Entre eles, três alunas com SD, de classes sociais diferentes, as três respectivas mães e quatro professoras, pois houve uma troca de professora com a mudança do ano letivo.

A amostra foi definida, tendo em mente a complexidade e exaustividade da pesquisa, pois se analisou a estimulação fornecida pelos pais durante as férias das alunas com SD, levando também em consideração a situação econômica das famílias e o grau de escolaridade dos pais.

A pesquisa iniciou-se em outubro de 2006 , com o auxílio das professoras, das mães e das próprias crianças SD que autorizaram a realização do estudo e publicação dos dados. No final do 40 bimestre de 2006, pesquisou-se e qualificou-se o aprendizado de três alunas SD. Refez-se a pesquisa e qualificou-se o aprendizado das três alunas SD, no início do ano letivo de 2007, a fim de verificar se houve retrocesso quanto aos conteúdos adquiridos antes das férias de verão. 
Cabe ressaltar que essas alunas com SD, participantes da pesquisa, estavam matriculadas em três escolas diferentes (duas públicas e uma particular), porém, ambas eram participantes da sala de recursos no contra turno na rede pública, (inclusive a aluna da escola particular).

A fim de preservar a identidade das alunas estudadas, denominaram-se as mesmas como alunas 01,02 e 03, relacionando com seu nível social, como seguem:

Aluna 01: nível social classe média, estudante de escola particular.

Aluna 02: nível social classe média alta; estudante de escola pública.

Aluna 03: nível social baixa, estudante de escola pública.

De posse dos dados coletados partiu-se para a análise destes, apoiados na revisão de literatura, conforme exposição no tópico de análise dos dados.

\section{Técnicas e instrumentos de coleta de dados}

Foram realizadas visitas às três escolas estudadas e às casas dos pais dos alunos com SD pesquisados, para aplicação de questionário e entrevista com estes mencionados, e também com suas professoras, com a finalidade de se coletar dados consistentes para a realização deste estudo.

Estes instrumentos de coleta de dados foram elaborados levando em consideração os seguintes aspectos:

- Conhecimentos adquiridos pelos alunos com SD durante o 4 bimestre do ano letivo de 2006;

- Percepção dos pais no tocante a importância da estimulação e qualidade de vida durante as férias escolares dos alunos com SD;

- Levantamento das atividades proporcionadas pelos pais durante as férias escolares dos alunos com SD;

- Existência da integração entre a escola e a família no processo de estimulação e qualidade de vida dos alunos.

- Conhecimentos dominados pelos alunos com SD no início do ano letivo de 2007.

É oportuno ressaltar que ambos os instrumentos de coleta de dados (questionário e entrevista) antes de sua aplicação com a amostra estudada, foram validados por uma especialista na área, por meio de uma aplicação piloto em outra escola especial. 


\section{Coleta de dados}

A coleta de dados ocorreu por meio da utilização dos instrumentos mencionados anteriormente, com as professoras, pais e alunos com SD participantes desta pesquisa, conforme descrito a seguir.

Para verificarmos os conhecimentos adquiridos durante o 40 bimestre de 2006, pelas alunas SD pesquisadas, aplicou-se no final deste período, um questionário semiestruturado, composto por oito questões, que as professoras participantes da pesquisa responderam, identificando e registrando, durante uma semana, os conhecimentos assimilados pelas alunas estudadas.

Para coletar informações a respeito da vida pessoal e estimulação fornecida pela família das alunas com SD durante as férias escolares, e integração da escola com a família no processo de ensino aprendizagem destes, realizou-se uma entrevista com as mães e professoras destas. Cada entrevista durou em média 30 minutos, onde foram anotadas as falas, pois a gravação poderia inibir os entrevistados.

Entrevistou-se as alunas para saber quais foram as atividades desenvolvidas nas férias escolares, proporcionadas pelas suas famílias. Bem como se indagou sobre a preferência destas entre as aulas ou as férias. Este momento de entrevista durou em média 15 minutos e não foi gravado pelo mesmo motivo exposto anteriormente.

Para constatar se houve retrocesso dos conteúdos assimilados antes das férias de verão de 2006, repetiu-se a pesquisa no inicio do ano letivo de 2007. Assim, ficou acordado com as professoras que durante as duas primeiras semanas de aulas, seria fornecido às alunas uma revisão de conteúdos ministrados no último bimestre de 2006. E durante este período, as professoras observariam essas alunas, verificando se houve algum prejuízo de conteúdo escolar durante as férias de verão.

Após esta observação as professoras preencheram outro questionário, composto por oito questões semiestruturadas que foram entregues às pesquisadoras três dias após sua entrega às professoras.

\section{Técnicas de análise de dados}

A etapa de análise dos dados consiste no tratamento dos dados obtidos por meio dos instrumentos de coleta (questionários e entrevistas). Nesta etapa, o pesquisador organiza e tabula os dados para posterior interpretação e correlação do material coletado com o propósito da pesquisa.

De acordo com Ludke e André (1986, p.45): 
"a tarefa de análise implica, num primeiro momento, a organização de todo o material, dividindo-o em partes, relacionando essas partes e procurando identificar nelas, tendências e padrões relevantes. Num segundo momento essas tendências e padrões são reavaliados buscando-se relações e inferências num nível de abstração mais elevado".

Assim, a análise abarca a execução de inferências acerca das questões apontadas na pesquisa, extraindo de documentos, entrevistas e questionários, indicadores que permitiram analisar a respeito da qualidade de vida que, alunos com SD, vivenciavam durante as férias de verão, e a sua influência no rendimento escolar, levando em consideração o estímulo recebido da família.

Para facilitar a tabulação dos dados, criou-se um arquivo de dados eletrônicos no aplicativo Excel da Microsoft. E assim organizaram-se as informações, relacionando cada questão do questionário e da entrevista com os aspectos estabelecidos.

A fim de preservar a identidade dos participantes desta pesquisa, classificaram-se as alunas SD entrevistadas como aluna 01, aluna 02 e aluna 03, bem como para suas mães foram denominadas mãe da aluna 01, mãe da aluna 02 e mãe da aluna 03. Cabe ressaltar ainda que esta pesquisa não foi submetida a um comitê de ética, estas recomendações foram sugeridas pela banca examinadora que aprovou esta pesquisa na forma de monografia de conclusão do curso de Pós-Graduação em Educação Especial de uma Faculdade privada no Estado do Paraná.

\section{Análise dos dados}

De posse dos dados tabulados, iniciou-se a etapa de análise. Essa etapa ocorreu amparada no escopo da pesquisa, ou seja, conforme os objetivos estabelecidos neste artigo. Para cada resposta obtida, confrontou-se com a literatura, conforme apresentado neste tópico.

\section{Pesquisa junto aos professores no final do $4^{\circ}$ bimestre de 2006, referente aos conteúdos assimilados pelos alunos com SD durante este período}

A pesquisa constatou que era unânime a preocupação dos professores, quando do retorno dos alunos SD, das férias de verão, quanto ao prejuízo dos conteúdos assimilados por estes, durante o último bimestre de 2006, pois como se tratava de alunos que necessitavam de reforço constante dos conteúdos ao longo do ano (e as escolas ofereciam materiais didáticos apropriados para este fim) não se sabia ao certo o que as famílias proporcionavam em casa para seus filhos com SD, durante este período de descanso. 
Os professores afirmaram que não conheciam as famílias das crianças SD, o que dificultava na interação escola - família. Pois não se tinha conhecimentos específicos das atividades, dos brinquedos e auxilio dos profissionais da saúde, que as famílias proporcionavam para as suas filhas com SD. Porém o conhecimento da vivência familiar da criança é importante. Segundo Anhão (2009), a aprendizagem da convivência e comportamentos sociais começa a ser aprendida ainda na infância no seio familiar e com a vizinhança, o que indica a importância da interação entre família e escola. Na fase infantil a aprendizagem vai depender das condições oferecidas em casa pela família e depois pela escola juntamente com a família.

Os professores acreditavam que algumas das famílias não pudessem oferecer a estimulação necessária ao pleno desenvolvimento de um aluno com SD. Tal preocupação se justifica, segundo Nunes e Dupas (2011), pois o nascimento da criança com deficiência traz uma sobrecarga para a família, necessitando maior envolvimento dos membros com cuidados diários e preocupação com o desenvolvimento da criança. Essa sobrecarga causa uma sensação de certas limitações restritivas devido ao compromisso se revelar prolongado, pois a criança dependerá por muito tempo de atenção diferenciada da família.

\section{Integração escola e família no processo de estimulação e qualidade de vida dos alunos com SD}

A pesquisa mostrou que, as escolas estudadas, tem ciência do seu papel educacional, proporcionando aos alunos com SD estimulação e subsídios para a qualidade de vida e desenvolvimento biopsicossocial destes, oferecendo-lhes materiais didáticos adequados para este fim.

As famílias, de modo geral, dentro das suas possibilidades e entendimento, reconhecem a importância das escolas e se preocupam com o bom desenvolvimento biopsicossocial e qualidade de vida de suas filhas com SD, inserindo-as na sociedade para que convivam com os colegas na escola, com familiares e vizinhos.

Durante as férias, foi constatado que as famílias proporcionavam às suas filhas com SD, as seguintes atividades de estimulação:

- Passeios em parques, museus da cidade, casa da irmã e revisão de conteúdos já estudados na escola, todas as semanas. (Relato da mãe da aluna 01).

- Compra de brinquedos educativos e passeios na casa de familiares (Relato da mãe da aluna 02).

- Brincadeiras com os primos e vizinhos e passeios ao museu e Recanto Prainha (Rio da cidade). (Relato da mãe da aluna 03). 
Valores morais e culturais também são incorporados às alunas com SD pelos pais e professores.

O que ficou evidente nesta pesquisa, é que nenhumas das professoras estudadas conversavam com as famílias sobre a importância da estimulação em casa, durante o ano letivo e/ou durante as férias escolares. O que ocorre são ações isoladas por parte das professoras e por parte das famílias, visando o desenvolvimento e promoção da qualidade de vida das alunas com SD.

Por outro lado, a pesquisa também apontou que os pais entrevistados, na sua maioria, procuravam espontaneamente a escola, não para fazer da sua casa uma extensão desta, buscando parcerias para desenvolver algumas habilidades e competências em conjunto, mas sim, buscando informações a respeito da evolução do processo ensino aprendizagem de suas filhas.

O que em outras palavras, significa dizer que, deixou a desejar a integração entre a escola e a família no processo de estimulação e qualidade de vida das alunas com SD. Ficando evidenciado nesta pesquisa, a importância e urgência em se estabelecer este laço, ação esta muito importante, conforme afirmação dos autores: Nunes e Dupas (2011), Cunha, Assis e Fiamenghi Jr (2002) e Moreira, EL-Hani e Gusmão (2000) e outros no referencial teórico deste artigo.

\section{Preocupação dos pais com a estimulação do aluno com SD no período de férias de verão}

O nascimento de uma criança com SD, geralmente, causa frustação aos pais, num primeiro momento, por se tratar de um ser "diferente", que requer alguns cuidados especiais.

De acordo com Asch (2003), a criança com alguma deficiência pode ter uma perspectiva de futuro com menos possibilidades com que seus pais e filósofos sonham. Mesmo assim, a deficiência pode restringir muito menos do que a sociedade e geneticistas afirmam.

Os pais devem procurar ajuda junto a profissionais e escolas especializadas em educação especial, visando o desenvolvimento pleno e inclusão das crianças com SD na sociedade. Tais ações para esta finalidade devem ser estimuladas não só nas escolas, mas em casa, pelos familiares. Isso vem ao encontro do que Nunes e Dupas (2011) e Cunha, Assis e Fiamenghi Jr (2002) afirmam no referencial teórico deste artigo.

Nesta pesquisa, observou-se que os pais entrevistados, na sua maioria, se preocupavam que as férias das suas filhas SD fossem agradáveis, proporcionando-lhes atividades de estimulação associado de qualidade de vida e ainda algumas atividades escolares, durante este período, para que quando estas, quando retornassem às escolas não apresentassem retrocesso quanto aos conteúdos assimilados no bimestre letivo anterior. 
Foi constatado ainda, que quanto maior o grau de instrução e condições financeiras dos pais, maior era a preocupação em relação às férias escolares de verão de sua filha com SD.

\section{Pesquisa junto aos alunos com SD}

Embora os pais deduzam que suas filhas com SD preferem a escola às férias escolares, a pesquisa demonstrou que estas se sentem ansiosos pelo início das férias. Uma aluna pesquisada pontuou que prefere as aulas, o que não significava dizer que esta não gostava das férias. As outras duas alunas entrevistadas alegaram que preferem as férias escolares, o que também não significava dizer que estas estavam insatisfeitas com a escola. Pelo contrário, estavam ansiosas pelo reinicio do ano letivo.

Quando do reinicio do ano letivo de 2007, a pesquisa retratou que as alunas com SD entrevistadas voltaram animadas para as escolas, relatando com detalhes as atividades e passeios realizados durante as férias escolares de 2006.

Foi constatado que as alunas com SD reconheceram as diferenças das atividades realizadas no período de aulas e as oferecidas pelos seus pais no período de férias escolares. Isso demonstra a preocupação dos pais, em desenvolver atividades educativas e estimulação, visando assegurar o rendimento escolar quando do retorno das férias escolares.

\section{Pesquisa junto aos professores no início do ano letivo de 2007 para saber se houve retrocesso quanto à aquisição dos conteúdos assimilados antes das férias de verão de 2006}

A pesquisa junto aos professores no reinicio do ano letivo de 2007 revelou que as alunas com SD voltaram das férias, animados, para cursar mais um ano letivo.

As duas primeiras semanas de aulas foram dedicadas, pelas professoras, como um período de revisão de conteúdos ministrados no último bimestre de 2006. Durante este período, os professores observaram as alunas com SD, verificando se houve algum prejuízo de conteúdo escolar durante as férias de verão.

Cabe ressaltar, que ambas as professoras acreditavam que as férias escolares de verão provocariam algum retrocesso de conteúdo escolar, nas alunas com SD. Tendo em vista o longo tempo afastadas das atividades escolares e de estimulação promovida pelas escolas.

Porém, a pesquisa revelou que não houve grande retrocesso no rendimento das alunas pesquisadas, apenas uma aluna estudada demonstrou algum retrocesso nos conteúdos já 
assimilados, mas com a revisão e auxílio de sua professora, esta logo foi se inteirando dos assuntos já abordados antes das férias. $O$ que nos permite inferir que o retrocesso não foi significativo.

Por fim, as professoras pontuaram a importância das férias escolares no processo de desenvolvimento cognitivo, escolar e social dos alunos SD. Estas entendem que neste período, a família deve exercer uma função "dobrada", pois além das obrigações de pais, estes devem ainda adicionar as funções de estimulação e educação, garantindo assim que suas filhas com SD tenham qualidade de vida e não apresentem retrocesso de conteúdos escolares na volta às aulas.

\section{Considerações finais}

Concluímos, com esta pesquisa, que o desafio de fazer com que um indivíduo com SD, receba estímulos e motivação necessária ao pleno desenvolvimento de suas capacidades e promoção da qualidade de vida é um dever tanto da escola como da família.

Para isto, faz-se necessário que a escola e a família estreitem seus laços, promovendo ações conjuntas, visando o desenvolvimento biopsicossocial destes indivíduos com SD. Essas ações para serem colocadas em prática, exigem que os envolvidos disponham de informações a respeito de métodos de ensino adequados e estimulação voltada para esta modalidade de educação especial.

Hoje, pode-se contar com uma gama de profissionais para fornecer informações e capacitações acerca da SD. E a pesquisa apontou que tanto a escola quanto a família estão recorrendo a estes profissionais, a fim de proporcionarem um efetivo desenvolvimento biopsicossocial destes indivíduos com SD, para que estes possam usufruir de seus direitos garantidos pela lei, porém as ações ainda ocorrem de maneira isolada.

No tocante ao impacto das férias de verão sobre as aquisições acadêmicas das alunas com SD, a pesquisa demonstrou que não houve perdas significativas de conteúdo, durante esse período em que a criança ficou sem contato com a escola, pois a família, de modo geral deu continuidade ao processo educativo, por meio de atividades diversas.

Esta pesquisa reforça a urgência em se desenvolver estudos mais exaustivos a respeito dos rótulos que são impostos às pessoas com deficiências e sobre a capacidade da família em oferecer estímulos adequados para que seus filhos se desenvolvam plenamente e com qualidade de vida. E ainda, quais as contribuições que a integração entre a escola e a família pode proporcionar a alunos com SD.

Acredita-se que o desenvolvimento destes estudos proporcionará um futuro promissor aos indivíduos com SD, bem como para as escolas, famílias e sociedade, pois os auxiliará a conquistarem sua independência e participação na sociedade, dentro das limitações de cada um. 


\section{Referências}

ANHÃO. P. P. G. O processo de interação social na inclusão escolar de crianças com Sìndrome de Down em educação infantil. Ribeirão Preto, 2009. Dissertação (Mestrado) - Programa de PósGraduação em Saúde na Comunidade, Universidade de São Paulo, Ribeirão Preto, 2009. Disponível em: <http://www.teses.usp.br/teses/disponiveis/17/17139/tde-28102009-151637/ptbr.php>. Acesso em: 11 dez. 2013.

ASCH, A. Diagnóstico pré-natal e aborto seletivo: um desafio à prática e às políticas. Physis: Revista de Saúde Coletiva. v. 13, n. 2, Rio de Janeiro, July/Dec. 2003. Disponível em:< http://www.scielo.br/pdf/physis/v13n2/a05v13n2.pdf>. Acesso em: 13 out. 2013.

BARTALOTTI, C. C. "Nenhum de nós é tão esperto como todos nós": construindo histórias de sucesso na inclusão de crianças com deficiência mental na creche. São Paulo, 2004. Tese (Doutorado) - Programa de Estudos Pós-Graduados em Educação: Psicologia da Educação, Pontifícia Universidade Católica de São Paulo, São Paulo, 2004.

CASTRO, A. S. A. ; PIMENTEL, S. C. Atendimento educacional específico Síndrome de Down: desafios e perspectivas na inclusão escolar. In: DIAZ, F. ; BORDAS, M. ; GALVÃO, N. ; MIRANDA, T. Deficiência e Contexto Social: questões contemporâneas. 1. ed. Salvador: EDUFBA, 2009. CUNHA, A. M. F. V. ; ASSIS, S. M. B. ; FIAMENGHI JR, G. A. Impacto da notícia da síndrome de Down para os pais: histórias de vida. Ciência \& Saúde Coletiva. V. 15, n. 2, Rio de Janeiro, mar. 2002. Disponível em:<http://www.scielo.br/scielo.php?script=sci_arttext\&pid=S141381232010000200021>. Acesso em: 10 out. 2013.

GARCIA, G. L. ; ROTH, M. G. M. ; SOBREIRO, B. P. Síndrome de Down: manual de orientação para pais. Pelotas: UFPEL, 1991.

GIL, A. C. Como elaborar projetos de pesquisa. São Paulo: Atlas, 2009.

LUDKE, M.; ANDRÉ, M. Pesquisa em educação: abordagens qualitativas. São Paulo: EPU, 1986.

LUIZ, F. M. R. et al. A inclusão da criança com Síndrome de Down na rede regular de ensino: desafios e possibilidades. Revista Brasileira de Educação Especial. v.14, n. 3, Marilia - São Paulo, sept./dez. 2008. Disponível em: <http://www.scielo.br/scielo.php?pid=S141365382008000300011\&script=sci_arttext>. Acesso em: 11 out. 2013.

MOREIRA, L. M. ; EL-HANI, C. N. ; GUSMÃO, F. A. A síndrome de Down e sua patogênese: considerações sobre o determinismo genético. Rev. Bras. Psiquiatr. [online].v. 22, n.2, 2000. Disponível em: <http://www.scielo.br/pdf/rbp/v22n2/a11v22n2>. Acesso em: 10 out. 2013. MOREIRA, L. M. ; GUSMÃO, F. A. Aspectos genéticos e sociais da sexualidade em pessoas com síndrome de Down. Revista Brasileira de Psiquiatria. V. 24, n. 2, São Paulo, Jun. 2002. Disponível 
em:< http://www.scielo.br/scielo.php?pid=S1516-44462002000200011\&script=sci_arttext>. Acesso em: 13 out. 2013.

MURTA, C. G. V; ÁVILA, M. A. P; MORON, A. F. Dopplervelocimetria do duto venoso no cálculo de risco para síndrome de down no primeiro trimestre da gravidez. Radiologia Brasileira. v. 35, n. 1, São Paulo, 2002. Disponível em: <http://www.scielo.br/scielo.php?pid=S141365382008000300011\&script=sci_arttext>. Acesso em: 11 out. 2013.

NUNES, M. D. R.; DUPAS, G. Independence of children with Down syndrome: the experiences of families. Revista Latino-Americana de Enfermagem, Ribeirão Preto, v. 19, n. 4, p. 985-993, jul./aug. 2011. Disponível em: <http://www.scielo.br/pdf/rlae/v19n4/18.pdf>. Acesso em: 24 maio 2012.

SILVA, R. N. A. A educação especial da criança com síndrome de Down. Rio de Janeiro, 2002. ZAQUEU, T. L. ; MELLO, L. E. Mal de Alzheimer - Síndrome de Down. Laboratório de Neurofisiologia; UNIFESP, 2008. Disponível em: <http://www.unifesp.br/dfisio/fisioneuro/sindrome_down.htm>. Acesso em: 17 jun. 2012.

Claudilene Aparecida Pandorf (UTFPR) possui graduação em Licenciatura em Educaçào Física pela Universidade Estadual de Ponta Grossa (1988). É Especialista em Educação Especial: atendimento as necessidades especiais pela Faculdade Iguaçu (2007). Atualmente é assistente em administração da Universidade Tecnológica Federal do Paraná. Mestranda do Programa de PósGraduação em Ensino de Ciência e Tecnologia. Email: claudilene@utfpr.edu.br.

Josiane Mello (UFRN), Mestre em Engenharia de Produção pela Universidade Tecnológica Federal do Paraná (2012), Especialista em Gestão Industrial - Conhecimento e Inovação pela mesma Universidade (2010), Especialista em Gestão de Bibliotecas Escolares pela Universidade Federal de Santa Catarina (2011) e Bacharel em Biblioteconomia pela mesma Universidade (2007). Atualmente é Bibliotecária-Documentalista da Universidade Federal do Rio Grande do Norte (UFRN), atuando na Divisão de Processos Técnicos. É consultora em normalização de trabalhos acadêmicos.

Email:

mellojosi@hotmail.com

Antonio Carlos de Francisco (UTFPR), Mestre em Tecnologia pela Universidade Tecnológica Federal do Paraná (1999) e doutor em Engenharia de Produção pela Universidade Federal de Santa Catarina (2003). Atualmente é professor do ensino básico, técnico e tecnológico da Universidade Tecnológica Federal do Paraná (UTFPR) e professor dos Programas de PósGraduação em Engenharia de Produção (Mestrado e Doutorado) e de Ensino de Ciência e 
Tecnologia (Mestrado Profissional) da UTFPR, Campus Ponta Grossa. Atua na área de Engenharia de Produção, principalmente nos seguintes temas: sustentabilidade, gestão do conhecimento, gestão da inovação, ensino de engenharia, qualidade de vida e qualidade de vida no trabalho; na área do Ensino de Ciência e Tecnologia na produção de metodologias e equipamentos para a melhoria da qualidade de ensino. Email: acfrancisco@utfpr.edu.br

Ana Cláudia de Oliveira (UTFPR), Mestranda em Engenharia de Produção pela Universidade Tecnológica Federal do Paraná. Graduada em Administração (2011). Atualmente é assistente em administração da Universidade Tecnológica Federal do Paraná. Email: anac@utfpr.edu.br.

Elson Heraldo Ribeiro Junior (UTFPR) Especialista em Gestão Industrial (Conhecimento e Inovação) pela Universidade Tecnológica Federal do Paraná (2009), graduado em Biblioteconomia pela Universidade Estadual de Londrina (2003). Email: elson@utfpr.edu.br. 